\title{
A Note on Dynamic Roy's Identity
}

\author{
Libo Xu' ${ }^{1}$, Kam $\mathbf{Y u}^{2}$ \\ ${ }^{1}$ Department of Economics, University of Calgary, Calgary, Canada \\ ${ }^{2}$ Department of Economics, Lakehead University, Thunder Bay, Canada \\ Email: libxu@ucalgary.ca, kam.yu@lakeheadu.ca
}

Received 18 May 2014; revised 26 June 2014; accepted 25 July 2014

Copyright (C) 2014 by authors and Scientific Research Publishing Inc.

This work is licensed under the Creative Commons Attribution International License (CC BY).

http://creativecommons.org/licenses/by/4.0/

c) (i) Open Access

\section{Abstract \\ We derive two forms of Roy's identity for a dynamic consumption model. The results are poten- tially useful in theoretical and empirical studies.}

\section{Keywords}

\section{Roy's Identity, Inter-Temporal Consumption}

\section{Introduction}

Roy's identity is a useful tool in theoretical and empirical studies of static consumption problems. Most dynamic consumer problems, however, concentrate on obtaining the optimal consumption path derived from the Euler equation. In this note we assume that the consumer makes decision in a two-stage process. In the dynamic stage, two forms of Roy's identity are derived. The first form relates the asset holding in each period to the marginal utility of interest rate and the marginal utility of income. The second form resembles the classic Roy's identity in the static analysis.

\section{Dynamic Roy's Identity}

The consumer is supposed to be making a two-stage decision. In the first stage, an inter-temporal decision on aggregate consumption and saving is made. Abstract from uncertainty about the future, a simple model of the decision problem can be set up as

subject to the budget constraints

$$
\max _{c_{t}, a_{t+1}} \sum_{t=0}^{\infty} \beta^{t} U\left(c_{t}\right),
$$

$$
a_{t+1}+c_{t}=m_{t}+\left(1+r_{t}\right) a_{t}, \quad t=0,1, \cdots,
$$


where $a_{t}, m_{t}$, and $r_{t}$ are exogenous asset, income, and interest rate respectively in period $t$, with $r_{0}=0$. The choice variables are $c_{t}$ and $a_{t+1}$. Utility is modelled by a stationary and separable discounted sum of utility function $U: \mathbb{R} \rightarrow \mathbb{R}$ in each period ${ }^{1}$. The Lagrangian is

$$
\mathcal{L}_{t}=\sum_{t=0}^{\infty}\left\{\beta^{t} U\left(c_{t}\right)+\lambda_{t}\left[m_{t}+\left(1+r_{t}\right) a_{t}-a_{t+1}-c_{t}\right]\right\} .
$$

The first-order conditions are

$$
\begin{aligned}
& \frac{\partial \mathcal{L}_{t}}{\partial c_{t}}=\beta^{t} U^{\prime}\left(c_{t}\right)-\lambda_{t}=0, \quad t=0,1,2, \cdots \\
& \frac{\partial \mathcal{L}_{t}}{\partial a_{t}}=\lambda_{t}\left(1+r_{t}\right)-\lambda_{t-1}=0, \quad t=1,2,3, \cdots,
\end{aligned}
$$

and the budget constraint (2).

The optimal solution is characterized by the Euler equation

$$
\frac{\beta U^{\prime}\left(c_{t+1}\right)}{U^{\prime}\left(c_{t}\right)}\left(1+r_{t+1}\right)=1,
$$

and the consumption function (in the case of constant interest rate)

$$
c_{t}=\frac{r}{1+r} W_{t}=r \sum_{s=0}^{\infty} \frac{m_{t+s}}{(1+r)^{s+1}}+r a_{t},
$$

which implies that in the steady state consumption in each period is a fixed portion of total wealth. The indirect utility function $V\left(r_{t}, m_{t}, a_{t}\right)$ is obtained by substituting $c_{t}$ in (6) into the objective function in (1).

In the second stage, the consumer makes decisions on how much to buy in $n$ number of goods and services in the market given the market prices $\mathbf{p}_{t}=\left(p_{1 t}, p_{2 t}, \cdots, p_{n t}\right)$ and the aggregate consumption $c_{t}$ in each period $t$. The model becomes the standard consumer optimization problem in microeconomics, that is,

$$
\max _{\mathbf{x}_{t}} u\left(\mathbf{x}_{t}\right)
$$

subject to

$$
\mathbf{p}_{t}^{\mathrm{T}} \mathbf{x}_{t}=c_{t}, \quad \mathbf{x}_{t} \in \mathbb{R}_{+}^{n} .
$$

The indirect utility function in each period $t$ is then

$$
v\left(\mathbf{p}_{t}, c_{t}\right)=\max _{\mathbf{x}_{t}}\left\{u\left(\mathbf{x}_{t}\right): \mathbf{p}_{t}^{\mathrm{T}} \mathbf{x}_{t}=c_{t}, \mathbf{x}_{t} \in \mathbb{R}_{+}^{n}\right\} .
$$

Roy's identity relates the optimal consumption of each good or service to the marginal disutility of price and the marginal utility of income, that is,

$$
x_{i t}^{*}=-\frac{\partial v\left(\mathbf{p}_{t}, c_{t}\right) / \partial p_{i t}}{\partial v\left(\mathbf{p}_{t}, c_{t}\right) / \partial c_{t}}
$$

for every good $i$ in every period $t$. In other words, consumption of each good depends on the consumer's preference structure and the relative price of the good to other goods and services.

Can we have Roy's identity for the inter-temporal consumption problem in the first stage? Apply the envelop theorem to (3), we have

$$
\frac{\partial V\left(r_{t}, m_{t}, a_{t}\right)}{\partial r_{t}}=\frac{\partial \mathcal{L}_{t}}{\partial r_{t}}=\lambda_{t} a_{t}
$$

${ }^{1}$ See, for example, [1] [2]. 
Substituting the first-order condition (4) into the above gives

$$
a_{t} U^{\prime}\left(c_{t}\right)=\frac{\partial V\left(r_{t}, m_{t}, a_{t}\right)}{\partial r_{t}}
$$

Similarly,

$$
U^{\prime}\left(c_{t}\right)=\frac{\partial V\left(r_{t}, m_{t}, a_{t}\right)}{\partial m_{t}} .
$$

Combining (8) and (9) gives the Roy’s identity for the inter-temporal consumption problem as

$$
a_{t}=\frac{\partial V\left(r_{t}, m_{t}, a_{t}\right) / \partial r_{t}}{\partial V\left(r_{t}, m_{t}, a_{t}\right) / \partial m_{t}} .
$$

It says that in any period if the consumer is in debt $\left(a_{t}<0\right)$, the marginal utility of an interest rate increase is negative.

A Roy's identity similar to the static form can be obtained by considering the "cake-eating" problem by assuming that income $m_{t}$ in the budget constraint (2) in each period is zero. Then the inter-temporal budget constraint is reduced to

$$
\sum_{t=0}^{\infty} \frac{c_{t}}{\prod_{j=0}^{t}\left(1+r_{j}\right)}=a_{0} .
$$

If we define

$$
\frac{1}{\prod_{j=0}^{t}\left(1+r_{j}\right)}=p_{t}, \quad t=0,1,2, \cdots,
$$

then the intertemporal utility maximization problem becomes

$$
\begin{gathered}
\max _{c_{t}} U\left(c_{0}, c_{1}, c_{2}, \cdots\right) \\
\text { subject to } \sum_{t=0}^{\infty} p_{t} c_{t}=a_{0} .
\end{gathered}
$$

Notice that $p_{0}=1$ since $r_{0}=0$. Starting in Period 1 , price of consumption is decreasing over time due to discounting. The indirect utility function can be expressed as

$$
V\left(p_{1}, p_{2}, \cdots, a_{0}\right)=\max _{c_{t}}\left\{U\left(c_{0}, c_{1}, c_{2}, \cdots\right): \sum_{t=0}^{\infty} p_{t} c_{t}=a_{0}\right\} .
$$

Roy's identity, in this case, is

$$
c_{t}^{*}=-\frac{\partial V\left(p_{1}, p_{2}, \cdots, a_{0}\right) / \partial p_{t}}{\partial V\left(p_{1}, p_{2}, \cdots, a_{0}\right) / \partial a_{0}} .
$$

\section{Conclusion}

We have used the envelop theorem to derive two forms of Roy's identity under an infinite horizontal consumption setting. In the first form, asset holding is related to the marginal utility of interest rate and marginal utility of income. The result can be used as a structural restriction on empirical analysis of inter-temporal consumption. In the second form prices are interpreted as future discount factors. The resulting form resembles the static Roy's identity. 


\section{References}

[1] Carter, M. (2001) Foundations of Mathematical Economics. The MIT Press, Cambridge.

[2] Wickens, M. (2011) Macroeconomic Theory: A Dynamic General Equilibrium Approach. 2nd Edition, Princeton University Press, Princeton. 
Scientific Research Publishing (SCIRP) is one of the largest Open Access journal publishers. It is currently publishing more than 200 open access, online, peer-reviewed journals covering a wide range of academic disciplines. SCIRP serves the worldwide academic communities and contributes to the progress and application of science with its publication.

Other selected journals from SCIRP are listed as below. Submit your manuscript to us via either submit@scirp.org or Online Submission Portal.
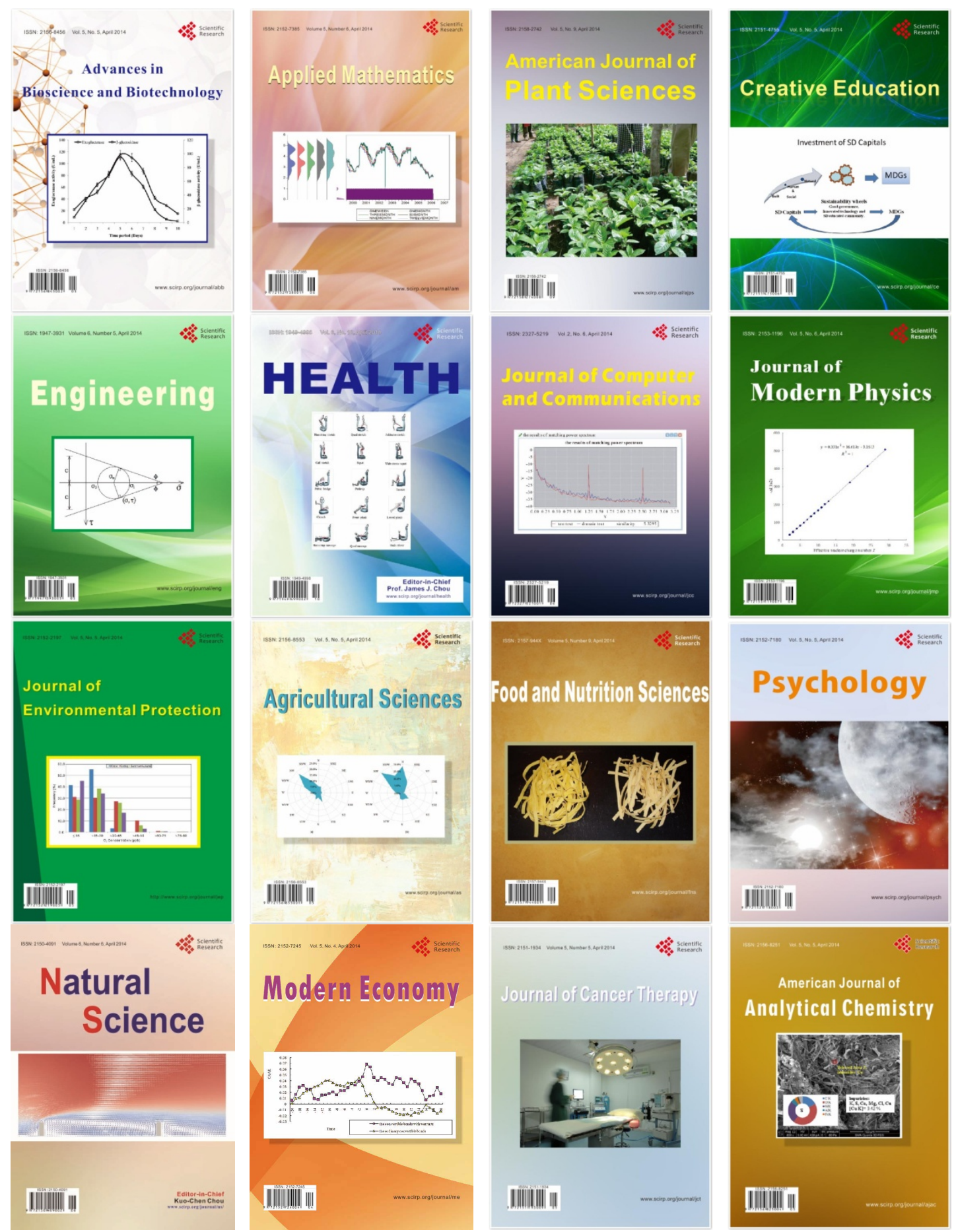